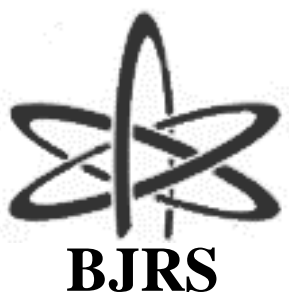
BRAZILIAN JOURNAL $\mathrm{OF}$ RADIATION SCIENCES 07-02B (2019) 01-13

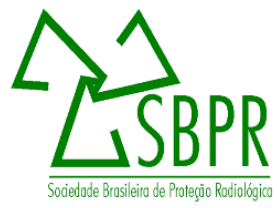

\title{
Simulation of a severe accident at a typical PWR due to break of a hot leg ECCS injection line using MELCOR code
}

\author{
S. M. Lee ${ }^{\text {a }}$ N.S. Lapa ${ }^{\text {b }}$ G. Sabundjian ${ }^{\mathrm{c}}$ \\ ${ }^{a, c}$ Instituto de Pesquisas Energéticas e Nucleares (IPEN / CNEN - SP) Av. Professor Lineu Prestes 2242 \\ 05508-000 São Paulo, SP. \\ ${ }^{b}$ Comissão Nacional de Energia Nuclear(CNEN) Rua General Severiano 90 22290-040 Rio de Janeiro, RJ.

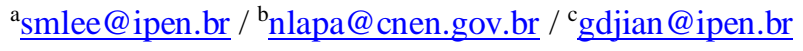

\begin{abstract}
This work aims to simulate a severe accident at a typical PWR of 1300 megawatts using the MELCOR code. The accident is assumed to be caused by a break in Emergency Core Cooling System line of a hot leg. The model for this typical PWR was elaborated by the Global Research for Safety which provided it to the CNEN for independent analysis of the severe accidents at Angra 2, which is similar to this typical PWR. Although both of them are not identical, the results obtained of that typical PWR may be valuable because of the lack of officially published simulation of severe accident at Angra 2. Relevant parameters such as pressure, temperature and water level in various control volumes, after the break at the hot leg, were calculated as well as degree of core degradation and hydrogen production within the containment during the accident. The simulation was able to reproduce the physical phenomena which were in general very reasonable, and most of the events occurred within acceptable time intervals. In addition, this scenario could be used as a basis for the study of the effectiveness of some preventive or/and mitigating measures of Severe Accident Management by adding each measure in the model. The uncertainty analysis was not carried out in this work.
\end{abstract}

Keywords: Severe Accident, MELCOR, SBLOCA, ECCS, SAMG.

ISSN: 2319-0612

Accepted: 2019-02-22 


\section{INTRODUCTION}

Severe accidents are beyond design basis accidents, which involve significant core degradation at nuclear power plant (NPP) [1]. The most recent example of this kind of accident occurred in Japan at the Fukushima Daiichi nuclear power station in March 2011.

Since the beginning of the present century Brazilian and international organizations which control the use of nuclear energy, i.e., the CNEN (Comissão Nacional de Energia Nuclear) and the International Atomic Energy Agency (IAEA) [2, 3, 4], respectively, have devoted efforts in performing simulations using computer codes for severe accidents at several nuclear installations. The MELCOR [5, 6], SCDAP/RELAP5 [7, 8], MAAP4 [9] and ASTEC [10] are the most widely used codes for this purpose.

Since all Brazilian nuclear power plants are pressurized water reactors (PWR), the efforts of the CNEN as well as of the IPEN (Instituto de Pesquisas Energéticas e Nucleares) are focused on accidents at reactors of this type, specifically on scenarios such as of station blackout (SBO), small break loss of coolant accident (SBLOCA). These are considered the most likely cases of this kind of accidents at a PWR. Obviously, other aggravating conditions must be added into these scenarios in order to lead the plant to a beyond design basis accident, such as loss of suction from the sump and/or from the residual heat removal (RHR) system.

The aim of this work is to simulate a basic scenario of SBLOCA, which consists of a break of Emergency Core Cooling System (ECCS) line of a hot leg at a typical PWR using MELCOR code. The model for this reactor is elaborated by the Global Research for Safety (GRS or Gesellschaft für Anlagen- und Reaktorsicherheit) in partnership with the CNEN. The same model represents a PWR, which is similar to Angra 2, but not identical. Figure 1 and Figure 2 show respectively the nodalization of the reactor cooling system (RCS) and of the containment of that typical PWR.

MELCOR is as well as MAAP and ASTEC one of the fast running integral computer codes, and it is developed at the Sandia National Laboratory (U.S.A) for the simulation of the relevant phenomena within light water reactor NPPs, either BWR or PWR, in a circumstance of severe accidents [11]. The calculations performed by means of the MELCOR code include a full range of 
physical phenomena, from thermal-hydraulics to fission product release and its transport [5]. The version used in this work is MELCOR 1.86.

\section{METHODOLOGY}

The simulated scenario is a basic one to which no preventive or mitigating measure was modelled, but rather some aggravating conditions were added, besides the break in the hot leg, in order to lead the system to a severe accident. It is imposed that the break takes place only in the control volume of number 200, that is, CV200, of the loop 1, as shown in Figure 1.

Figure 1: Nodalization of primary and secondary circuit of the PWR

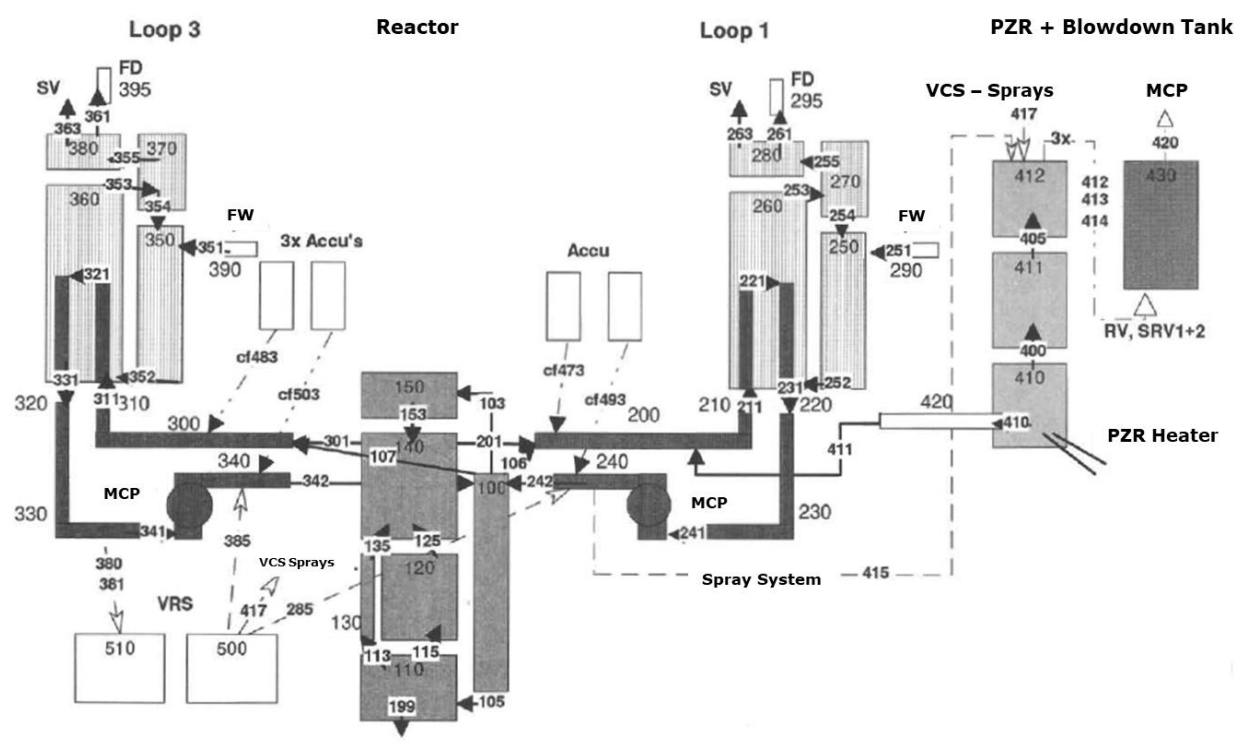

Source: Global Research for Safety

The ECCS lines are not represented by control volumes, but their effect is modelled by means of control functions simulating mass sources inside the respective hot (or cold) legs; thus, they are not explicitly shown in Figure 1. The flow path area of the physical ECCS injection line at the hot leg is $380 \mathrm{~cm}^{2}$ and it was assumed that the break consisted of its total separation from the hot leg pipe. 
Therefore, the break is of guillotine type, but it takes place in the ECCS line and not in the hot leg itself. Thus, at the moment of the break $(\mathrm{t}=0 \mathrm{~s})$, a mass flow is initiated between CV200 and the containment compartment which encompass the hot leg, namely, the CV003, as shown in Figure 2. Obviously, the area of this flow path is the same to that of the physical ECCS injection line, i.e., $380 \mathrm{~cm}^{2}$. Although the flow path is not shown in either figures, its area is controlled by a control function, which itself consists of a tabular function (TF).

Figure 2: Nodalization of containment, annulus and auxiliary building of the PWR.

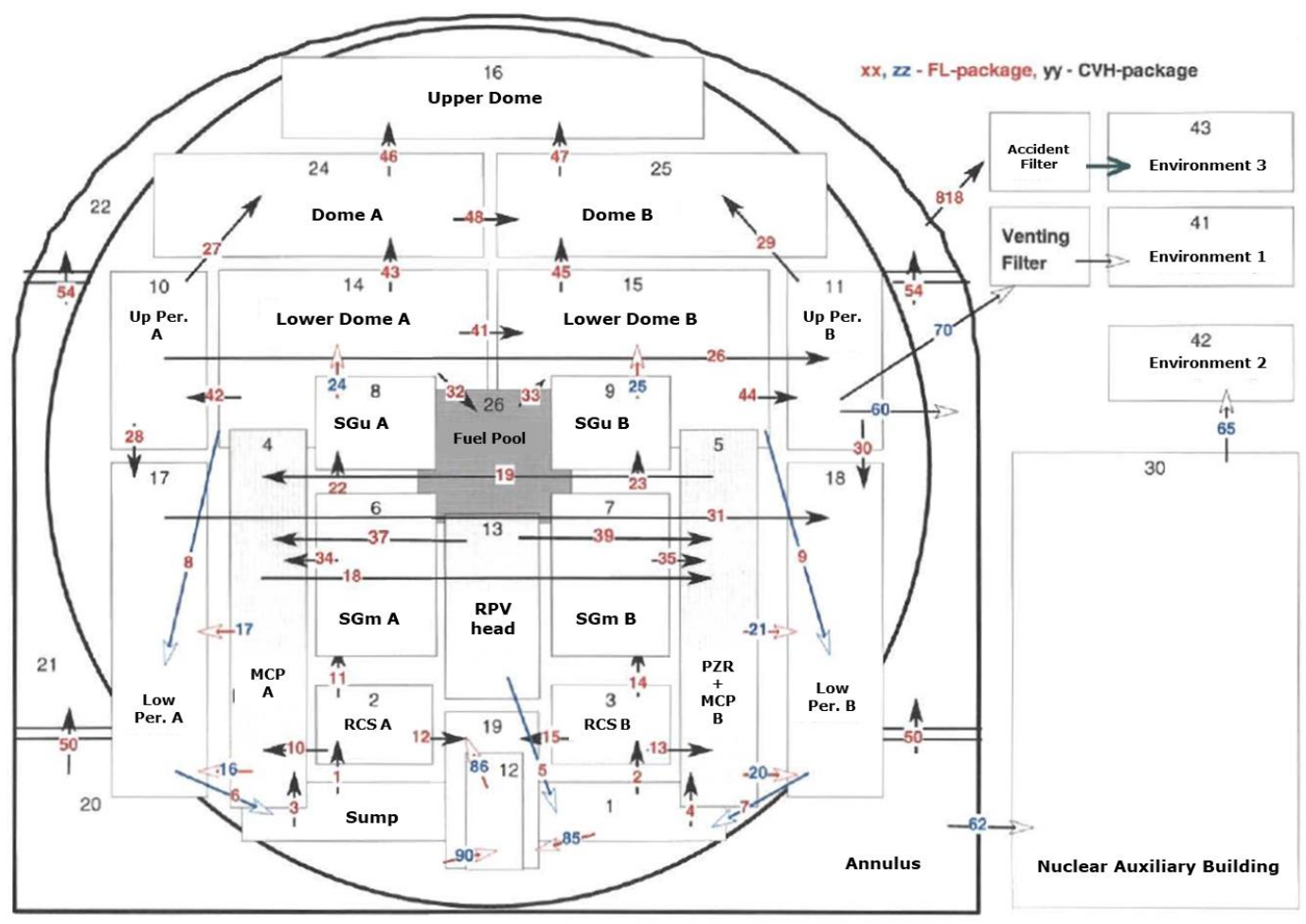

Source: Global Research for Safety

Even though the break size is considerable, this scenario is commonly classified as SBLOCA due to the fact that the area of the leak is smaller than one tenth of the total flow area of the hot leg pipe, namely, $4418 \mathrm{~cm}^{2}$. 
As mentioned before, some additional postulations are made besides in order to lead the NPP to a severe accident. Thus, the following boundary conditions were:

a. Turbine bypass not available;

b. Condenser not available;

c. Loss of suction from the sump and RHR;

d. ECC injection from Refueling Water Storage Tank (RWST) by Safety Injection Pump (SIP) and by RHR pump available;

e. All accumulators available.

The simulation was performed considering a single model for the reactor cavity, whereas the subdivision into three parts of the same is desirable in order to get more realistic outcome. In addition, the simulation was carried out on a personal computer with Intel(R) Core(TM) i5-3570 CPU 3.40GHz during about 202 hours, using various time steps, and the problem time of the simulation was 144 hours.

\section{RESULTS AND DISCUSSION}

The magnitude of the break is reflected by the fast depressurization in the RCS as can be observed in Figure 3. Pressures in RPV and pressurizer drop from about 160 to 97 bar within 10 seconds, and then decrease still rapidly to about 3.5bar within 5 minutes. On the other hand, the pressures in steam generators (SG) leap from 63 to 84bar at 40s, and decrease almost linearly to around 10bar. This depressurization in the SGs is due to the reverse heat transfer, from secondary to primary side. The hottest cladding and fuel reach $2171^{\circ} \mathrm{C}$, and the maximum temperature attained inside the core is $2765^{\circ} \mathrm{C}$, as shown in Figure 4. Also, as can be seen in Figure 5, the degradation of the core starts at $2 \mathrm{~h} 50 \mathrm{~m}$, when the temperatures of the cladding and fuel attain around $1800^{\circ} \mathrm{C}$. The core is completely melted down at $4 \mathrm{~h} 18 \mathrm{~m}$ and, at the same moment, the corium falls into the lower plenum (LPL) and it causes a slight increase of pressure in the RCS (see Figure 3) due to the evaporation of the residual water, which dries up at $4 \mathrm{~h} 25 \mathrm{~m}$. The RPV failure occurs at around $8 \mathrm{~h}$. 
Figure 3: Pressure in RPV, Pressurizer, $S G$ and FWT.

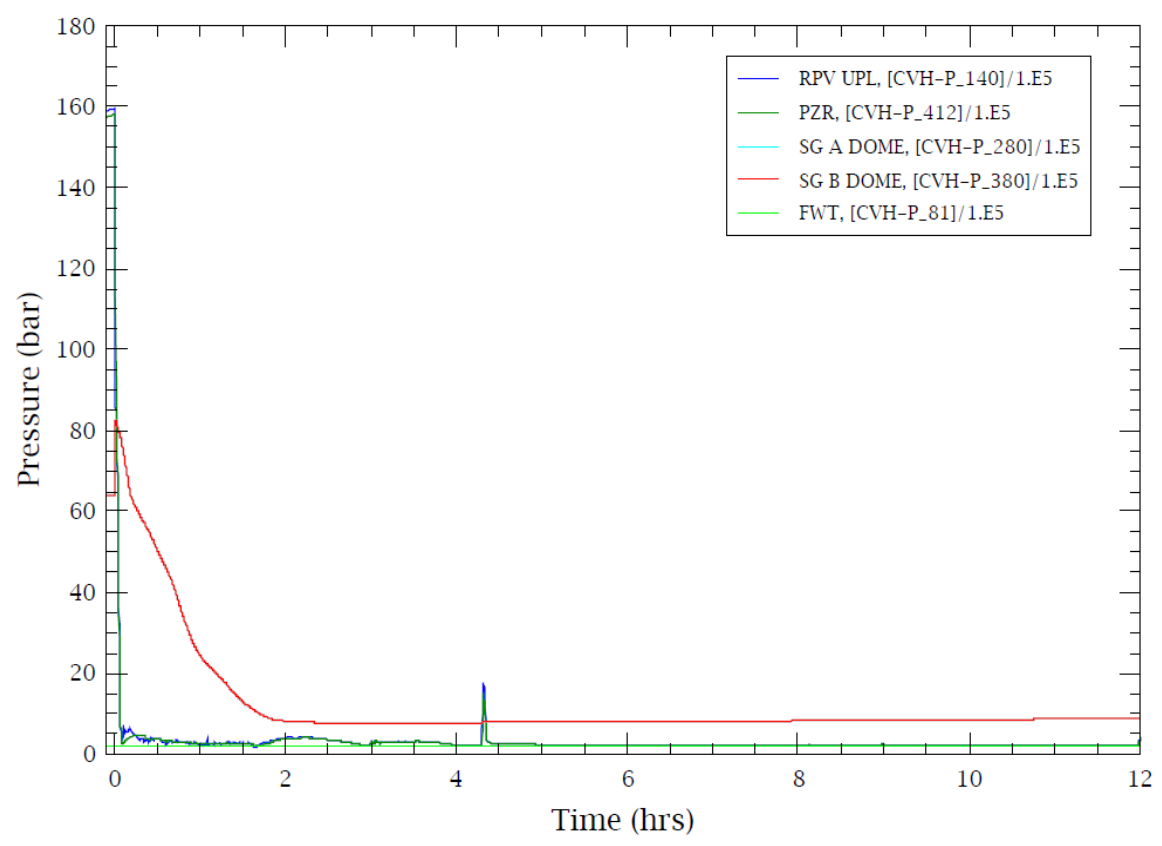

Figure 4: Maximum Temperatures of Cladding, Fuel and the Core.

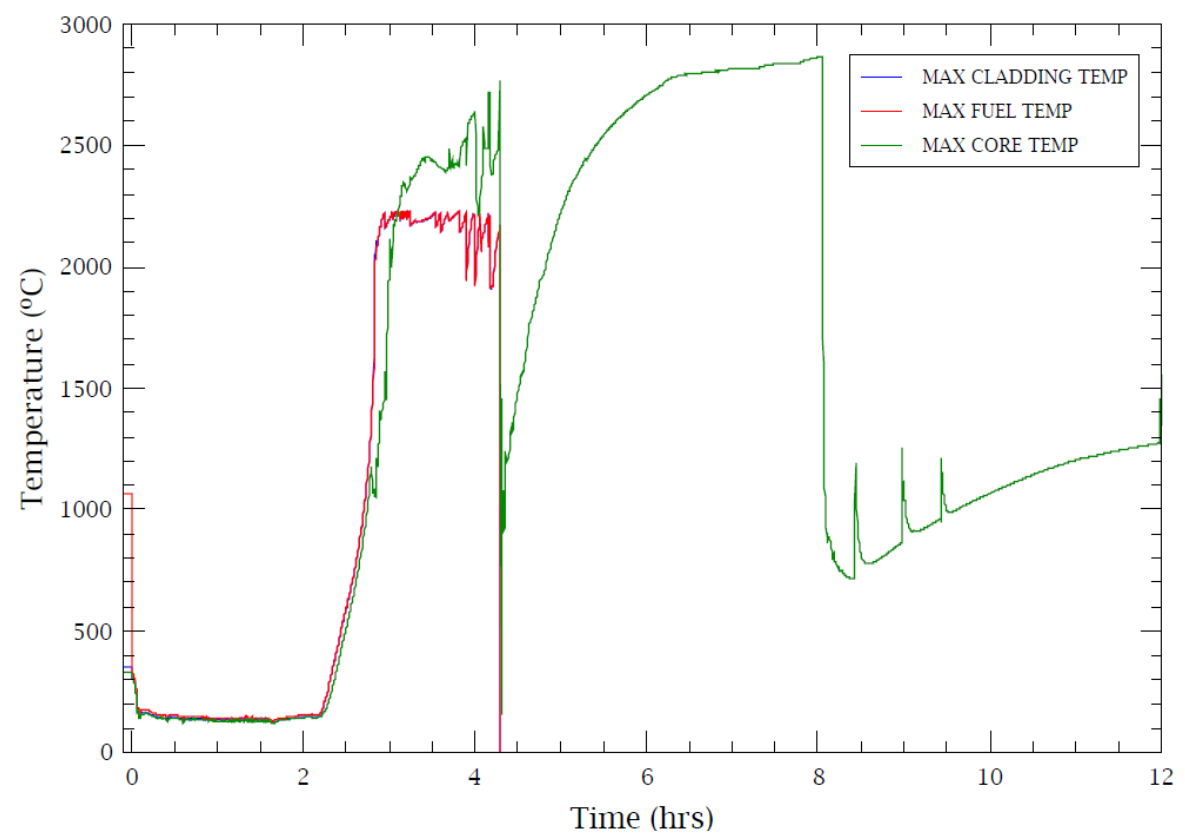


Figure 5: Degree of the core degradation.

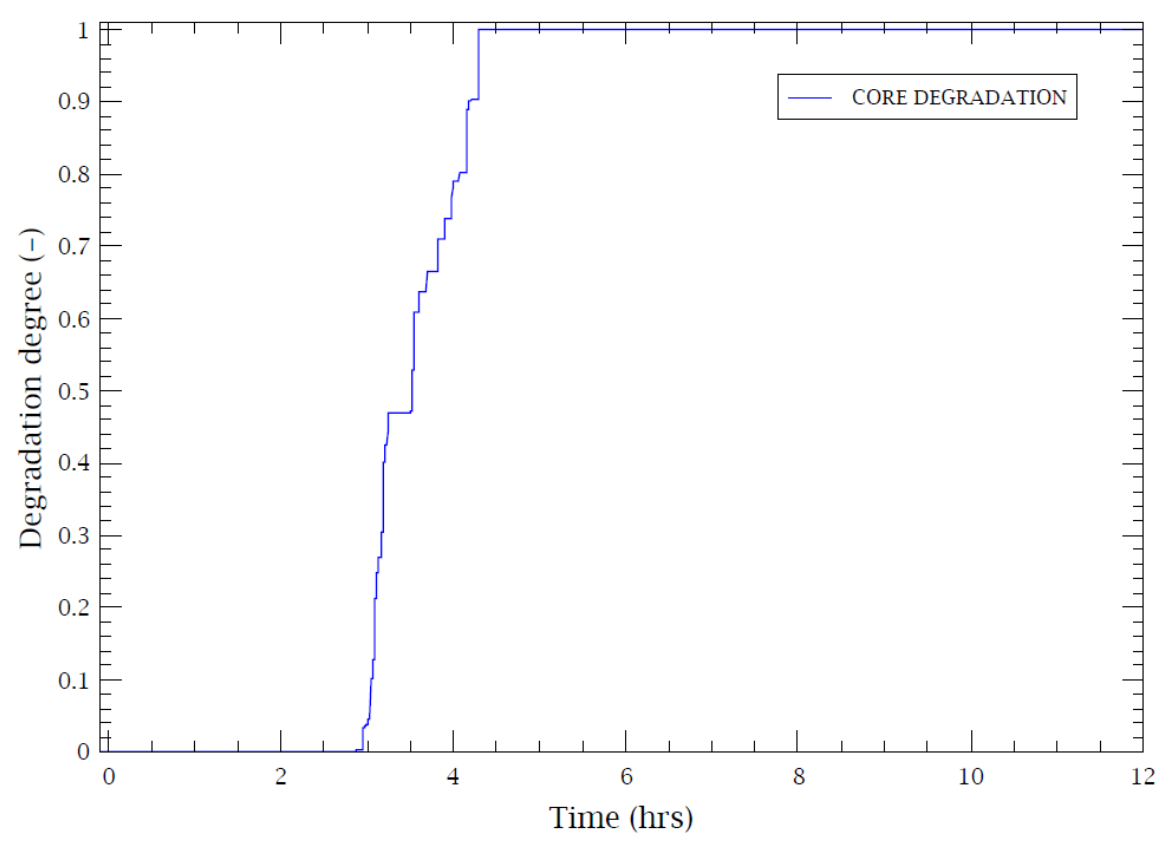

Figure 6 presents water level of the core and RCS during the first 24 hours. According to the figure, the RPV water is emptied soon after the complete core degradation and remains empty until the ingression of the sump water, which starts at $15 \mathrm{~h} 20 \mathrm{~m}$. Moreover, the pressurizer is emptied at $17 \mathrm{~h}$. The total amount of hydrogen produced inside the core due to the oxidation of the metallic structure by steam is $785.56 \mathrm{~kg}$, as presented in Figure 7. The production of hydrogen and carbon monoxide due to the molten core concrete interaction (MCCI) during the whole calculation is shown in Figure 8.

Immediately after the break of the ECCS, the containment pressure jumps to 3.15bar as illustrated in Figure 9, but it drops down due to the rapid condensation of the leaked steam by the metallic structure in the containment and to the ECCS injection. However, after the end of the ECCS injection, the pressure increases again and suffers a peak at $4 \mathrm{~h} 18 \mathrm{~m}$ reflecting the relocation of the melted core into the LPL, as mentioned above. The temperatures of the diverse compartments of the containment are shown in Figure 10. Furthermore, as the consequence of the absence of filtered containment venting system (FCVS), the pressure increases above 6bar, which is the set point of a typical FCVS, and the pressure continues increasing linearly with time, as shown in Figure 11. 
Figure 6: Water level in hot legs, core and pressurizer

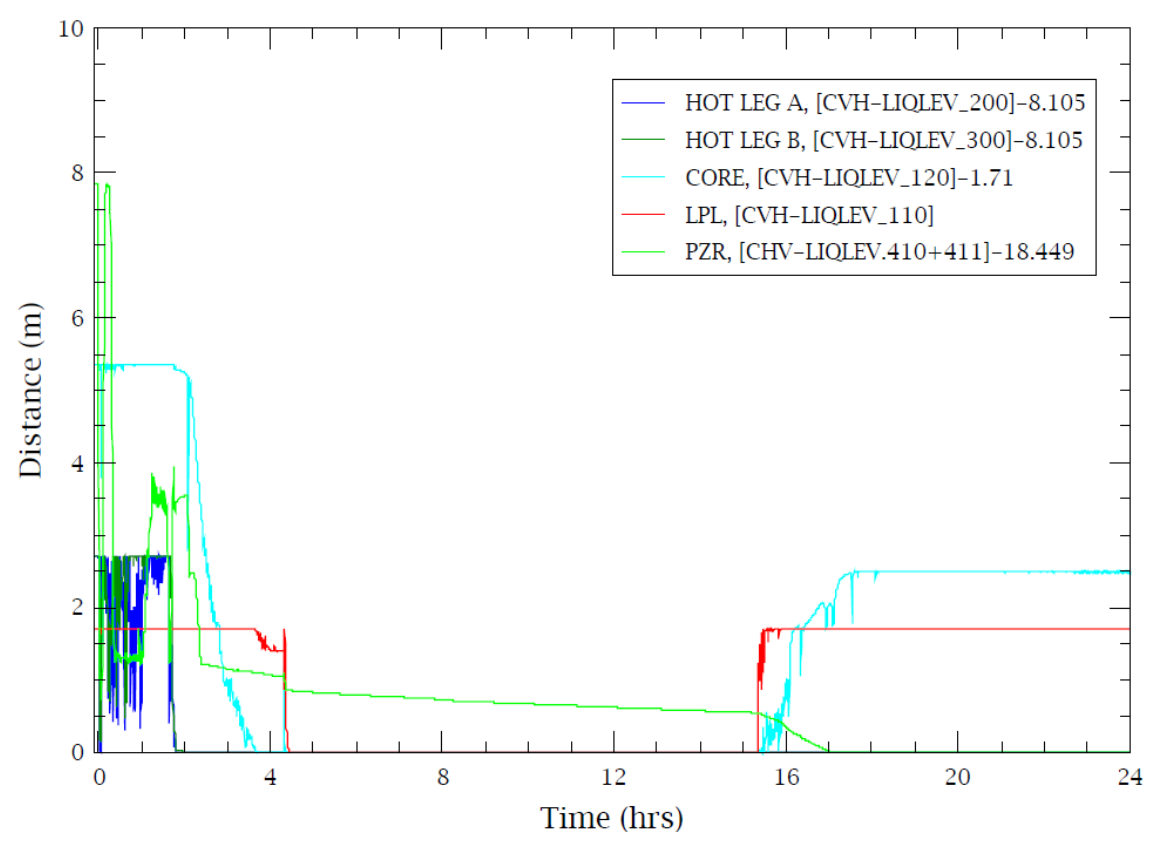

Figure 7: Generated $\mathrm{H}_{2}$ and $\mathrm{CO}$ (short term).

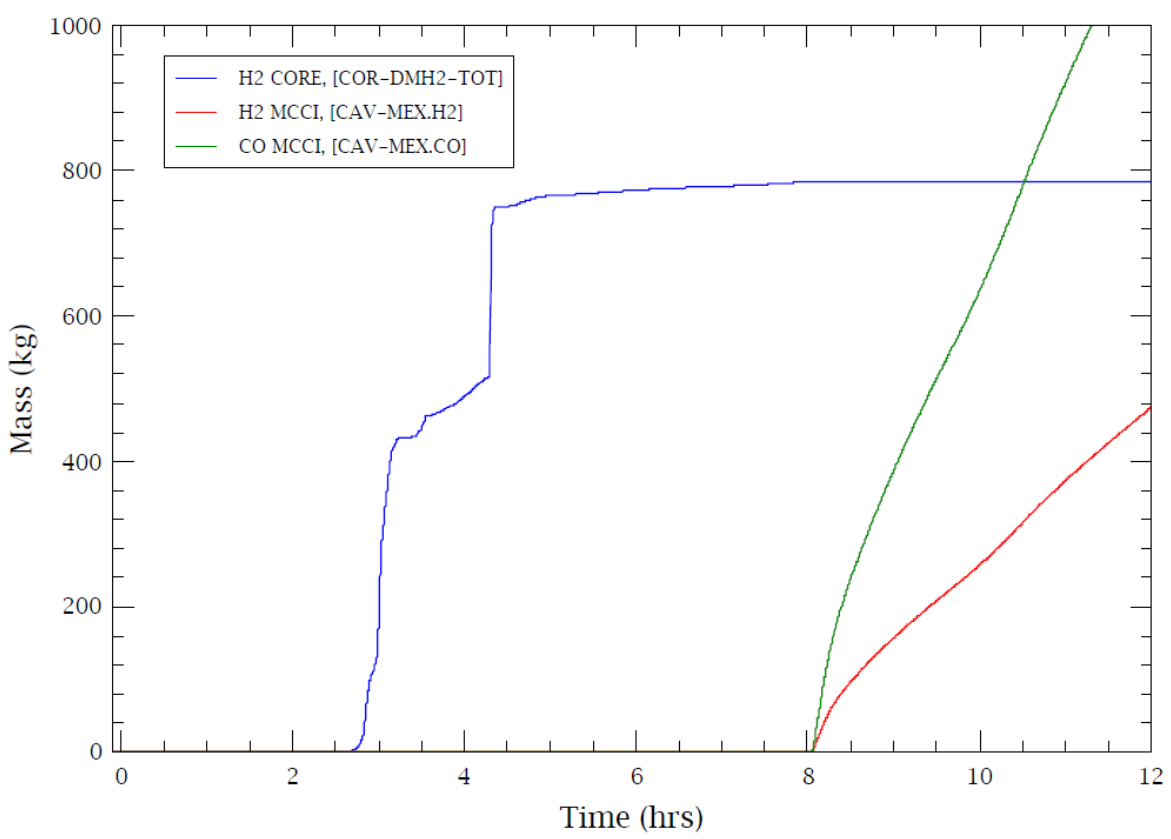


Figure 8: Generated $\mathrm{H}_{2}$ and $\mathrm{CO}$ (long term).

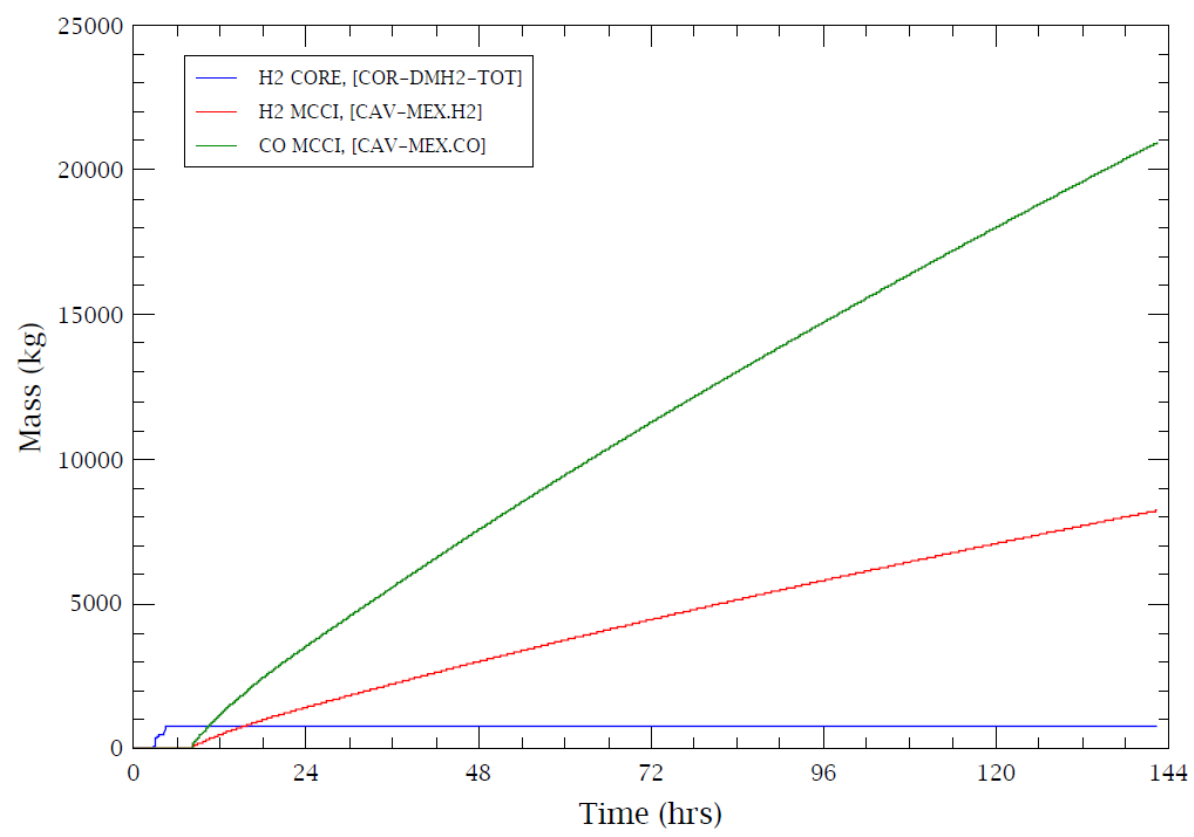

Figure 9: Containment Pressure (short term).

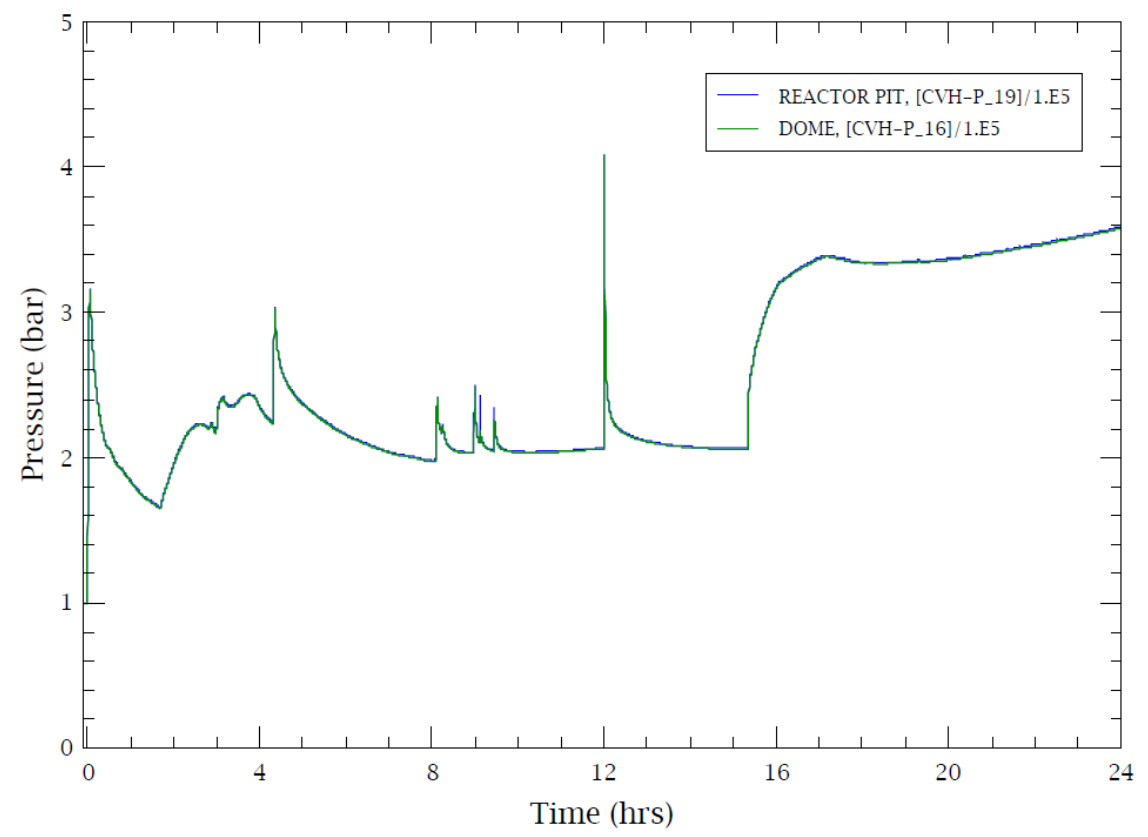


Figure 10: Containment atmosphere temperature (short term).

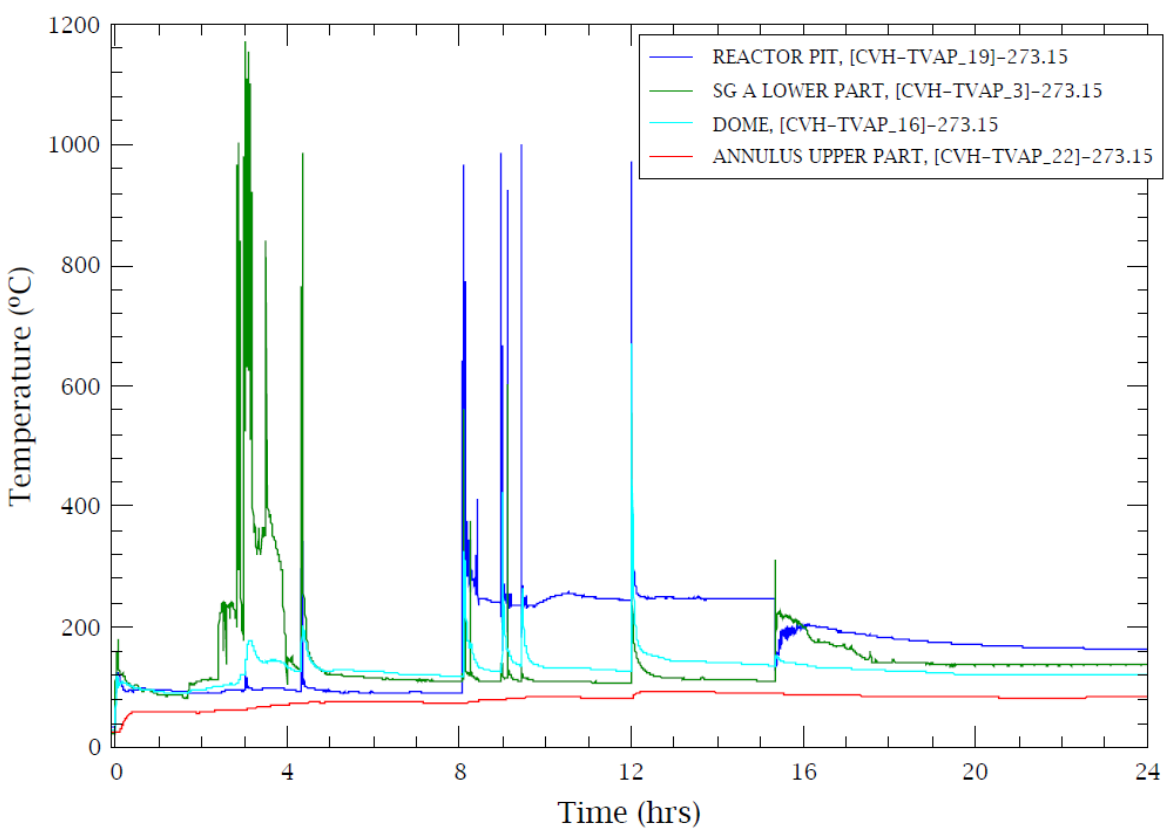

Figure 11: Containment Pressure (long term).

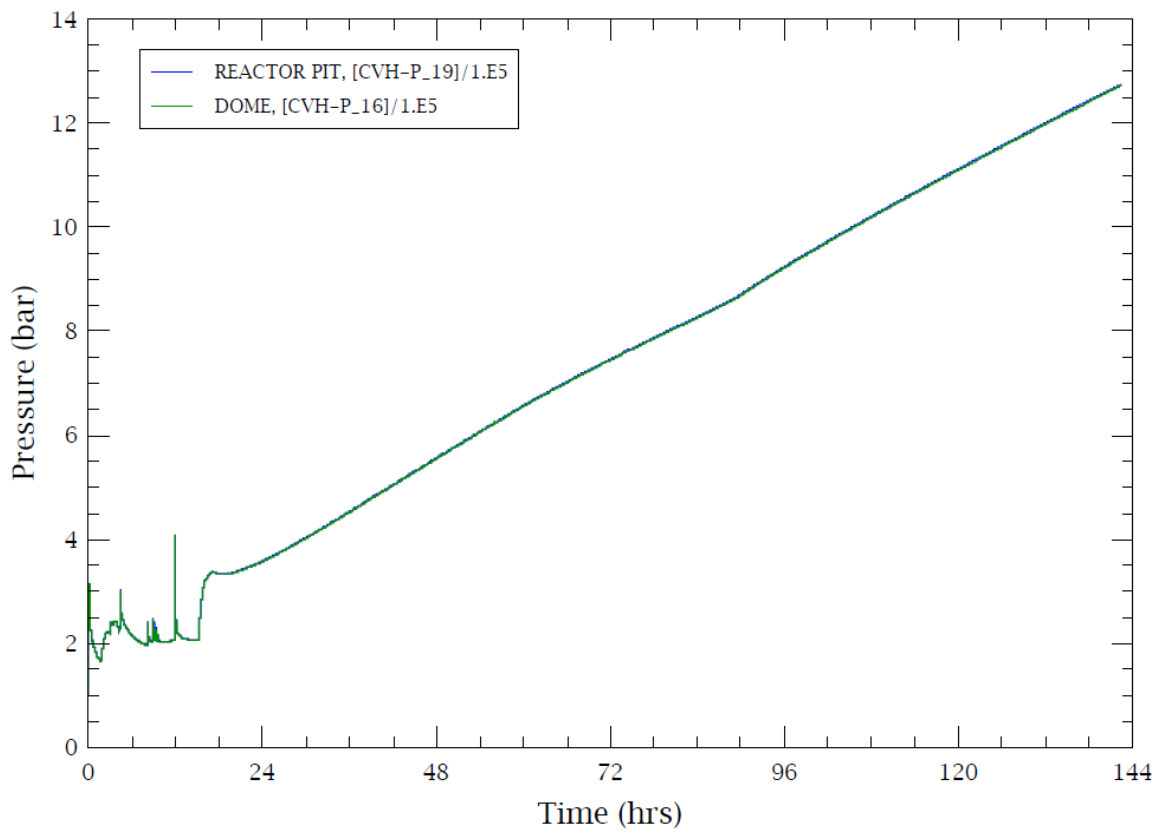


The results of the simulation are summarized below in Table $\mathbf{1 .}$

Table 1: Summary of results of the scenario.

\begin{tabular}{lc}
\hline \multicolumn{1}{c}{ Event / Quantity } & Time (hh:mm:ss) / Mass (kg) \\
\hline Start of core heat-up & $02: 11: 00$ \\
Start of core degradation & $02: 49: 59$ \\
Start of hydrogen production & $02: 38: 40$ \\
End of core degradation & $04: 18: 08$ \\
Melt relocation into the LPL & $04: 18: 08$ \\
Complete emptying of LPL & $04: 26: 40$ \\
RPV failure & $08: 02: 54$ \\
Start of MCCI & $08: 02: 55$ \\
Ingression of sump water into the reactor pit & $15: 20: 00$ \\
Containment pressure > 6.0bar & $53: 20: 00$ \\
Produced hydrogen mass until RPV failure (kg) & 785.56 \\
\hline
\end{tabular}

\section{CONCLUSION}

The main aim of this simulation was achieved since it had reproduced successfully the purposed severe accident. It was shown that the postulated break of ECCS line and the imposed additional conditions were sufficient to cause the meltdown of the core, the RPV failure and the production of considerable amount of hydrogens; eventually resulting in the overpressure inside the containment beyond the set point for the opening of FCV. As already mentioned, both mitigating and preventive measures can be implemented in the input deck used for this calculation, as well as further aggravating conditions, in order to evaluate their effectiveness by comparison with this basic scenario. It is expected that improvement in model, such as subdivision of the reactor cavity, will produce more reliable and realistic result. Concerning reliability, uncertainty analysis that is missing in this work should be the only way to validate the obtained result. By the way, the use of the model applied in 
this simulation for an independent severe accident analyses for Angra 2 still demands implementation of several data of this NPP in the input deck.

\section{ACKNOWLEDGMENT}

To the ELETROBRAS ELETRONUCLEAR/CAPES and to the Centro de Engenharia Nuclear of the IPEN for the financial support.

To Dr. Thomas Steinrötter for the MELCOR training and valuable advice.

\section{REFERENCES}

1. International Atomic Energy Agency. IAEA safety glossary: Terminology used in nuclear safety and radiation protection, Vienna, IAEA, 2007.

2. International Atomic Energy Agency. Implementation of accident management programmes in nuclear power plants, Safety Report Series 32, Vienna, IAEA, 2004.

3. International Atomic Energy Agency. Severe accident management programmes for nuclear power plants, Safety Guide NS-G-2.15, Vienna, 2008.

4. International Atomic Energy Agency. IAEA report on severe accident management in the light of the accident at the Fukushima Daiichi nuclear power plant, INTERNATIONAL EXPERTS MEETING, Vienna, 2014.

5. Gauntt, R.O., Cole, R.K., et al. MELCOR computer code manuals, Vol.1: Primer and User's Guide, $2^{\text {nd }}$ Revision, Albuquerque, Sandia National Laboratory, 2000.

6. Gauntt, R.O., Cole, R.K., et al. MELCOR computer code manuals, Vol.2: Reference manuals, $2^{\text {nd }}$ Revision, Albuquerque, Sandia National Laboratory, 2000.

7. Allison, C.M., et al. SCDAP/RELAP5/MOD3.1 code manual, Vol. 2: Damage Progression Model Theory, Idaho Falls, Idaho National Engineering Laboratory, 1993.

8. Allison, C.M., et al. SCDAP/RELAP5/MOD3.2 code manual, Vol. 1-5 (NUREG/CR-6150), Idaho Falls, Idaho National Engineering Laboratory, 1998. 
9. Fauske \& Associates, Inc. MAAP4-Modular Accident Analysis Program for LWR plants, code manual, Vol. 1-4, Palo Alto, EPRI, 1994.

10.Allelein, H.J., et al. Severe Accident Code ASTEC Development and Validation, Paris, EUROSAFE, 1999.

11. International Atomic Energy Agency. Approaches and tools for severe accident analysis for nuclear power plants, Safety Reports Series 56, Vienna, IAEA, 2008. 